\title{
COMMENTARY
}

\section{Value of Autopsy Emphasized in the Case Report of a Single Patient with Middle East Respiratory Syndrome}

David H. Walker

From the Department of Pathology and Center for Biodefense and Emerging Infectious Diseases, University of Texas Medical Branch, Galveston, Texas

A single research-oriented autopsy of a patient with Middle East respiratory syndrome (MERS) defined the pathologic basis of this disease, which has affected approximately 1500 individuals and caused $>500$ deaths. The pathogenesis of MERS is partially revealed in this investigation by identification of the target organ, lung, and the target cells, type 2 pneumocytes and bronchial submucosal glands, the likely source of virus that results in person-to-person transmission. The study also strongly supports dipeptidyl peptidase 4 (DPP4) as the host receptor for the virus. The truth-testing of this human autopsy highlights the valid and discordant characteristics of animal models in nonhuman primates, transgenic mice expressing the host receptor for MERScoronavirus $(\mathrm{CoV})$, and rabbits. The long interval between the emergence of this dangerous disease 3 years ago and the first autopsy reminds us of the lost opportunity that the decline of the performance of autopsies, particularly research-oriented postmortem examinations in the United States, represents.

\section{Overview of MERS}

The article by $\mathrm{Ng}$ et $\mathrm{al}^{1}$ in this issue of the American Journal of Pathology exemplifies the value of a well-performed study of an autopsy. Despite nearly 1500 cases of MERS and $>500$ deaths, this is the only report of an autopsy.

MERS is caused by MERS-CoV that is reminiscent of the severe acute respiratory syndrome-CoV that appeared in China after spreading from an origin in bats by undetermined means into live animal markets where civet cats were an amplifying host, leading to human infections and personto-person spread globally. After $>8000$ cases with a $10 \%$ case fatality rate, severe acute respiratory syndrome was controlled and has not reappeared. In contrast, MERS appeared in the Middle East in 2012 with most cases occurring in Saudi Arabia and the United Arab Emirates and continues to reemerge from its amplifying host, camels, with both camel-to-human and nosocomial and household contact human-to-human transmission occurring. ${ }^{2,3}$ MERS has spread to at least 24 other countries, including the United States and South Korea, where $>180$ cases arose from a single infected individual who had returned from travel to the Middle East. ${ }^{4}$

Although MERS occurs in only $4 \%$ of household contacts, nosocomial outbreaks occur particularly when infection control measures are deficient. Thus, although the average number of cases generated from one infected individual with MERS is $<0.7$, indicating that person-to-person spread dies out, the occurrence of new cases of camel-tohuman transmission continues.

Although the case fatality rate of laboratory-confirmed MERS is $35 \%$, there are many asymptomatic and mild infections in contacts. In fact, MERS is diagnosed most often in elderly men and individuals with comorbidities, including type 2 diabetes mellitus, chronic renal failure, chronic cardiac disease, hypertension, chronic pulmonary disease, and obesity, and individuals who are immunocompromised. The clinical manifestations of MERS are principally respiratory. The symptoms are nonspecific, including fever, chills, nonproductive cough, and dyspnea. Clinical worsening over a few days leads to respiratory failure with diffuse rales and

Accepted for publication November 23, 2015.

Disclosures: None declared.

Address correspondence to David H. Walker, M.D., University of Texas Medical Branch, 301 University Blvd., Galveston, TX 77555-0609. E-mail: dwalker@utmb.edu. 
radiographic abnormalities similar to other viral pneumonias and acute respiratory distress syndrome. Patients also manifest tachypnea, tachycardia, and hypotension. Patients often develop acute renal failure and gastrointestinal symptoms, including nausea, vomiting, and/or abdominal pain. The main mode of transmission remains unknown, although it appears to be via large droplets of respiratory secretions and direct contact, although airborne transmission may also play a role.

\section{Pathologic Findings from a Single Patient Autopsy}

The value of a well-designed and performed single autopsy study is well illustrated in this report of a research-oriented autopsy that was performed under less than ideal conditions as revealed by the lack of a means for weighing the organs and the 10-day postmortem interval before performance of the autopsy. ${ }^{1}$ The article by $\mathrm{Ng}$ et $\mathrm{al}^{1}$ revealed the nature of the disease through the pathologic lesions and supplied critical knowledge for understanding the pathogenesis by identifying the target organ and target cells by immunohistochemistry and visualization of the $\mathrm{CoV}$ in lung lesions by electron microscopy. ${ }^{1}$ The pathology in this fatal case of MERS included exudative diffuse alveolar damage with hyaline membranes, pulmonary edema, type 2 pneumocyte hyperplasia, interstitial pneumonia that was predominantly lymphocytic, and multinucleate syncytial cells. These lesions comprise the concrete pathologic basis for the patient's respiratory failure and radiologic abnormalities. Bronchial submucosal gland necrosis was also observed. Note that neither acute renal lesions nor central nervous system lesions were identified.

The target organ in this patient, the lungs, and the target cells of infection were identified by immunohistochemical detection of MERS-CoV antigens in pneumocytes, multinucleate epithelial syncytial cells, and bronchial submucosal glands. Infection of bronchial submucosal glands is a likely source of viral shedding in respiratory secretions, leading to human-to-human transmission. MERS-CoV antigens colocalized with surfactant-antigen containing type 2 pneumocytes and syncytial cells but not in pulmonary macrophages. DPP4, the receptor for MERS-CoV spike protein S1 subunit, colocalized with MERS-CoV antigen-containing pneumocytes and syncytial cells. This viral tropism is the pathogenic basis for the respiratory manifestations of MERS. No MERS-CoV antigen was detected in kidney, small intestine, colon, liver, spleen, or lymph nodes.

\section{Implications of the Pathologic Findings}

The data from this study are discordant with some hypotheses that have been suggested for MERS. No MERS-CoV infection was detected in the kidney, and no acute renal lesions were present, which contrasts with the rare detection of viral RNA in urine of patients. ${ }^{5}$ Acute renal failure is a frequent manifestation of severe cases of MERS as occurred in this patient, but the pathophysiologic explanation would appear more likely to be the effects of hypotension on renal function rather than direct viral infection of the kidney, at least in this case. Similarly, the absence of infection in the intestines contrasts with the rare detection of viral RNA in stool and suggests that nausea, vomiting, and abdominal pain, which occur not infrequently in patients with MERS, are unlikely to be caused by viral infection of the gastrointestinal tract.

Many in vitro studies of MERS-CoV infection of various cell types were performed and interpreted to suggest viral tropism for various organs for which the autopsy study provided no support. For example, in vitro infection of dendritic cells and macrophages has resulted in dysregulation in the production of cytokines and antigen presentation, and infection of $\mathrm{T}$ lymphocytes induced apoptosis. ${ }^{6}$ The observations reported in the spleen and lymph nodes of this case do not support the relevance of these studies in human infection. Of course, these conclusions could change with further studies of larger series of cases of MERS.

\section{Strengths and Limitations of MERS Animal Models}

It is ironic that animal models of MERS were developed in nonhuman primates, mice, and rabbits without knowledge of the viral pathogenesis and pathologic lesions of MERS$\mathrm{CoV}$-infected humans. An appropriate animal model of an infectious disease should represent the clinical course, organ tropism of the agent, cellular tropism of intracellular agents such as viruses, and pathologic lesions of the human disease after inoculation of an appropriate dose of the agent by the appropriate route that represents the most likely mode of transmission and portal of entry of the agent. There should be an incubation period and duration of illness that agree reasonably with the human course of infection and dosedependent severity, including ideally sublethal and lethal doses. DPP4, the host cell receptor for MERS-CoV, ${ }^{7}$ varies among animal species with the receptors of mice, ferrets, and hamsters failing to bind the virus, rendering these species resistant to infection in contrast with the receptors of camels, humans, rhesus monkeys, common marmosets, and rabbits which bind the virus, making the animals susceptible to infection.

After combined intranasal, intratracheal, oral, and ocular inoculation or only intratracheal inoculation of an extremely high dose of virus, rhesus macaques develop a mild illness shortly ( 1 or 2 days) later with viral replication limited to the respiratory tract (nasal mucosa, conjunctiva, and lung), radiographic pneumonia, histopathologic interstitial pneumonia, and viral antigen in type 1 and 2 pneumocytes and alveolar macrophages. ${ }^{8}$ This model represents self-limited 
human MERS as occurs in healthy immunocompetent females and likely differs from most infections in humans by the large dose of inoculum, short incubation period, and infection of alveolar macrophages.

Common marmosets inoculated with a large viral dose via combined intranasal, ocular, oral, and intratracheal routes developed moderate-to-severe disease that required euthanasia of two of nine animals on day 4 after a short incubation period with radiographic bilateral pneumonia and viral RNA in nasal and oropharyngeal swabs, blood, respiratory tract, gastrointestinal tract, kidney, heart, adrenal gland, liver, spleen, and brain. ${ }^{9}$ Multifocal moderate-tomarked acute interstitial pneumonia on days 3 and 4 was followed by fibrinous consolidation on day 6 . Viral antigen was identified in pulmonary lesions, especially type 1 pneumocytes and alveolar macrophages. This model represents severe human disease and pathologic lesions, and it likely differs from human infection in the high dose of inoculum, short incubation period and course, evidence for widely disseminated infection, and infection of predominantly type 1 pneumocytes and alveolar macrophages. A subsequent study of MERS-CoV infection in common marmosets found sublethal mild-to-moderate respiratory disease with no recovery of infectious virus or detection of viral RNA by RT-PCR or viral antigens by immunohistochemistry, modest radiographic evidence of pulmonary disease, and multifocal interstitial pneumonia with few syncytial cells. ${ }^{10}$ Both studies found clinical respiratory disease, although differing in severity of illness and virologic results. Development of a nonhuman primate model that is consistently severe will require further investigation and attention to the pulmonary pathology, target cells, and viral dissemination or lack thereof.

Because mice are resistant to MERS-CoV, owing to the attachment domain of the viral spike protein not binding to the murine DPP4 receptor, the human DPP4 gene has been expressed in mice. The first successful approach was transduction of mouse lungs by intranasal inoculation of a replication deficient adenovirus vector that express the DPP4 protein. ${ }^{11}$ MERS-CoV replicated in the lungs of these mice and was cleared with only mild clinical signs within 6 to 8 days in young mice and 10 to 14 days in aged mice. Subsequently, transgenic mice were generated that express human DPP4 in all tissues. Intranasal inoculation of a high dose of virus in these mice (eventually shown to be 100,000 $\mathrm{LD}_{50}$ ) resulted in a severe illness with a short incubation period and $100 \%$ lethality on day $6 .{ }^{12}$ Viral RNA was detected in many organs, and infectious virus was isolated from lungs and brain. Moderate interstitial pneumonia on day 2 progressed with viral antigen detected in type 1 and 2 pneumocytes and microglia, neurons, and astrocytes.

A subsequent study of these transgenic mice determined the median infectious dose and $\mathrm{LD}_{50}$ and investigated the events after intranasal inoculation of MERS-CoV. ${ }^{13}$ Five of eight mice inoculated with 10 median tissue culture infectious doses of virus died between days 8 and 13. All mice inoculated with $10 \mathrm{LD}_{50}$ of virus died between days 6 and 12. Infectious virus was recovered from the lungs of only two of eight mice and the brain of only one of these mice. None had viral antigen detected in the lung or brain by immunohistochemistry, although viral RNA was uniformly detected in all lung samples and in the brain and gastrointestinal tract samples from days 6 through 10. Pulmonary histopathology progressed from mild multifocal perivascular, peribronchial, and interstitial mononuclear cell infiltrates on day 2 to a peak on day 8. Beginning on day 6 the brain contained pathologic lesions, including perivascular cuffing, apoptotic bodies, microglial activation, and mild meningitis. This transgenic mouse model effectively represents dose-dependent lethal and sublethal MERS-CoV pneumonia with dose-dependent incubation and appropriate pulmonary target cells. Disseminated infection and pathology in the brain were not observed in the human autopsy report; thus, they diverge from the current knowledge of what an ideal model should contain. In addition, infection of the gastrointestinal tract was not observed in the human autopsy. Clearly further autopsy studies are needed to establish firmly the spectrum of human pathology and organ involvement in MERS.

Infection of rabbits with a high dose of MERS-CoV resulted in subclinical pulmonary infection without observed histopathologic lesions. ${ }^{14}$ Excretion of virus from the upper respiratory tract suggested a potential means of transmission. This model may accurately represent what occurs in asymptomatic human infections.

The report by $\mathrm{Ng}$ et $\mathrm{al}^{1}$ emphasizes the importance of defining a novel disease. Until the target organs and the nature of the damage are determined, one does not in reality understand a disease. In the case of MERS development of numerous animal models was undertaken before knowledge of the human pathology. Although these experimental studies were able to suggest the target cells of the virus and histopathology of MERS, only some of the features of the animal models conform to the observations in the human autopsy. Until the truth-testing of a large series of autopsies is reported, judgment will favor those models supported by the observations in a single postmortem examination. Note that the experimental in vitro, in vivo, and structural evidence for DPP4 as a receptor for the MERS-CoV is supported by the autopsy study.

\section{Challenges in Studying Infectious Diseases}

Indeed, it is unfortunate that there is inadequate knowledge of the pathology of other emerging infectious diseases. Human monocytic ehrlichiosis, a prevalent life-threatening disease in the United States, is an example. Our own studies of several lethal, sublethal, persistent, and tick-transmission mouse models of ehrlichiosis have determined the pathology and pathogenic and immune mechanisms in mice that are far less understood in the human infections. ${ }^{15-17}$ Despite thousands 
of cases with a $10 \%$ case fatality rate in China, our knowledge of the pathology of severe fever and thrombocytopenia syndrome virus infection is limited to a report of a few cases in Japan. ${ }^{18,19}$

We pathologists cannot feel too superior as the decline of autopsies in the United States is dramatic compared with the past. Our potential loss of knowledge includes loss of the opportunity to evaluate the effects of new treatments and the correlations with new imaging tools. An even greater lost opportunity is the inadequate use of autopsies as prospective research tools. The decline in performance of autopsies has resulted in the erosion of expertise of many pathologists whose sporadic assignment to cover an autopsy falls outside their areas of expertise, which is often the surgical pathologic diagnoses of a single organ rather than the comprehensive analysis of the pathophysiologic and morphologic changes in all of the organ systems accrued over a lifetime. The consideration of further reduction in the autopsy requirement for training pathology residents may portend further retreat from the potential gains in knowledge that well-performed postmortem examinations can provide.

Because there is only one autopsy report of a novel disease that has killed $>500$ individuals in the past 3 years should awaken our attention to the value of this final procedure in the search for new medical knowledge. It also supports the careful use of some of the current animal models for development and testing of vaccine candidates and novel therapeutics for the prevention and treatment of the pulmonary disease caused by MERS-CoV.

\section{Acknowledgment}

I thank Angela Culler for her exceptional administrative assistance.

\section{References}

1. Ng DL, Al Hosani F, Keating MK, Gerber SI, Jones TL, Metcalfe MG, Tong S, Tao Y, Alami NN, Haynes LM, Mutei MA, Wareth LA, Uyeki TM, Swerdlow DL, Barakat M, Zaki SR: Clinicopathologic, immunohistochemical, and ultrastructural findings of a fatal case of Middle East respiratory syndrome coronavirus infection in United Arab Emirates, April 2014. Am J Pathol 2016, 186:652-658

2. Zumla A, Hui DS, Perlman S: Middle East respiratory syndrome. Lancet 2015, 386:995-1007

3. Chan JF, Lau SK, To KK, Cheng VC, Woo PC, Yuen KY: Middle East respiratory syndrome coronavirus: another zoonotic betacoronavirus causing SARS-like disease. Clin Microbiol Rev 2015, 28:465-522

4. Majumder MS, Kluberg SA, Mekaru SR, Brownstein JS: Mortality risk factors for Middle East respiratory syndrome outbreak, South Korea, 2015. Emerg Infect Dis 2015, 21:2088-2090

5. Drosten C, Seilmaier M, Corman VM, Hartmann W, Scheible G, Sack S, Guggemos W, Kallies R, Muth D, Junglen S, Muller MA, Haas W, Guberina H, Rohnisch T, Schmid-Wendtner M, Aldabbagh S, Dittmer U, Gold H, Graf P, Bonin F, Rambaut A, Wendtner CM: Clinical features and virological analysis of a case of Middle East respiratory syndrome coronavirus infection. Lancet Infect Dis 2013, $13: 745-751$
6. Chu H, Zhou J, Wong BH, Li C, Chan JF, Cheng ZS, Yang D, Wang D, Lee AC, Li C, Yeung ML, Cai JP, Chan IH, Ho WK, To KK, Zheng BJ, Yao Y, Qin C, Yuen KY: Middle East respiratory syndrome coronavirus efficiently infects human primary $\mathrm{T}$ lymphocytes and activates the extrinsic and intrinsic apoptosis pathways. J Infect Dis 2015. doi:10.1093/infdis/jiv380

7. Raj VS, Mou H, Smits SL, Dekkers DH, Muller MA, Dijkman R, Muth D, Demmers JA, Zaki A, Fouchier RA, Thiel V, Drosten C, Rottier PJ, Osterhaus AD, Bosch BJ, Haagmans BL: Dipeptidyl peptidase 4 is a functional receptor for the emerging human coronavirus-EMC. Nature 2013, 495:251-254

8. de Wit E, Rasmussen AL, Falzarano D, Bushmaker T, Feldmann F, Brining DL, Fischer ER, Martellaro C, Okumura A, Chang J, Scott D, Benecke AG, Katze MG, Feldmann H, Munster VJ: Middle East respiratory syndrome coronavirus (MERS-CoV) causes transient lower respiratory tract infection in rhesus macaques. Proc Natl Acad Sci U S A 2013, 110:16598-16603

9. Falzarano D, de Wit E, Feldmann F, Rasmussen AL, Okumura A, Peng X, Thomas MJ, van Doremalen N, Haddock E, Nagy L, LaCasse R, Liu T, Zhu J, McLellan JS, Scott DP, Katze MG, Feldmann H, Munster VJ: Infection with MERS-CoV causes lethal pneumonia in the common marmoset. PLoS Pathog 2014, 10: e 1004250

10. Johnson RF, Via LE, Kumar MR, Cornish JP, Yellayi S, Huzella L, Postnikova E, Oberlander N, Bartos C, Ork BL, Mazur S, Allan C, Holbrook MR, Solomon J, Johnson JC, Pickel J, Hensley LE, Jahrling PB: Intratracheal exposure of common marmosets to MERSCoV Jordan-n3/2012 or MERS-CoV EMC/2012 isolates does not result in lethal disease. Virology 2015, 485:422-430

11. Zhao J, Li K, Wohlford-Lenane C, Agnihothram SS, Fett C, Zhao J, Gale MJ Jr, Baric RS, Enjuanes L, Gallagher T, McCray PB Jr, Perlman S: Rapid generation of a mouse model for Middle East respiratory syndrome. Proc Natl Acad Sci U S A 2014, 111:4970-4975

12. Agrawal AS, Garron T, Tao X, Peng BH, Wakamiya M, Chan TS, Couch RB, Tseng CT: Generation of a transgenic mouse model of Middle East respiratory syndrome coronavirus infection and disease. J Virol 2015, 89:3659-3670

13. Tao X, Garron T, Agrawal AS, Algaissi A, Peng BH, Wakamiya M, Chan TS, Lu L, Du L, Jiang S, Couch RB, Tseng CK: Characterization and demonstration of value of a lethal mouse model of Middle East respiratory syndrome coronavirus infection and disease. J Virol 2016, 90:57-67

14. Haagmans BL, van den Brand JM, Provacia LB, Raj VS, Stittelaar KJ, Getu S, de Waal L, Bestebroer TM, van Amerongen G, Verjans GM, Fouchier RA, Smits SL, Kuiken T, Osterhaus AD: Asymptomatic Middle East respiratory syndrome coronavirus infection in rabbits. J Virol 2015, 89:6131-6135

15. Olano JP, Wen G, Feng HM, McBride JW, Walker DH: Histologic, serologic, and molecular analysis of persistent ehrlichiosis in a murine model. Am J Pathol 2004, 165:997-1006

16. Ismail N, Soong L, McBride JW, Valbuena G, Olano JP, Feng HM, Walker DH: Overproduction of TNF-alpha by CD8+ type 1 cells and down-regulation of IFN-gamma production by CD4+ Th1 cells contribute to toxic shock-like syndrome in an animal model of fatal monocytotropic ehrlichiosis. J Immunol 2004, 172:1786-1800

17. Saito TB, Walker DH: A tick vector transmission model of monocytotropic ehrlichiosis. J Infect Dis 2015, 212:968-977

18. Yu XJ, Liang MF, Zhang SY, Liu Y, Li JD, Sun YL, et al: Fever with thrombocytopenia associated with a novel bunyavirus in China. N Engl J Med 2011, 364:1523-1532

19. Hiraki T, Yoshimitsu M, Suzuki T, Goto Y, Higashi M, Yokoyama S, Tabuchi T, Futatsuki T, Nakamura K, Hasegawa H, Saijo M, Kakihana Y, Arima N, Yonezawa S: Two autopsy cases of severe fever with thrombocytopenia syndrome (SFTS) in Japan: a pathognomonic histological feature and unique complication of SFTS. Pathol Int 2014, 64:569-575 